\title{
PULMONARY ARTERY AND AORTIC DIAMETERS; MEASUREMENT WITH CALCULATION OF MAIN PULMONARY ARTERY TO ASCENDING AORTA RATIO IN HEALTHY CHILDREN, USING CT AS DIAGNOSTIC MODALITY
}

Faran Nasrullah', Rashid Mahmood ${ }^{2}$, Shahlisa Hameedi ${ }^{3}$

1. MBBS, FCPS

Consultant Radiologist, Dept of Radiology, Combined Military Hospital, Peshawar.

2. MBBS, FCPS Consultant Radiologist Dept of Radiology, Combined Military Hospital, Peshawar.

3. BDS, MPH

Assistant Professor Islamabad Medical \& Dental College, Islamabad.

Correspondence Address: Dr. Faran Nasrullah, Dept of Radiology, PAF Hospital Rafiqui, Shorkot. Faran.nas@gmail.com

Article received on: 12/05/2017

Accepted for publication: 15/08/2017

Received after proof reading: 06/10/2017

\begin{abstract}
Objectives: To measure pulmonary artery and aortic calibers, and calculating main pulmonary artery to ascending aorta ratio in healthy children, to verify the adult ratio of 1:1. Study Design: Observational study. Place and duration of study: Radiology Department, Combined Military Hospital, Peshawar from 15 July 2015 to 14 July 2016. Methodology: Chest CT cans of 283 healthy children, with no history or predisposing causes of pulmonary hypertension, performed between July 2015 and July 2016, were retrospectively studied. Diameters of pulmonary artery and aorta were measured on CT chest, at the level of bifurcation of the main pulmonary artery, and the ratio of pulmonary artery to ascending aorta was calculated. Results: The average diameter of the main pulmonary artery, right pulmonary artery and left pulmonary artery were $19 \mathrm{~mm}, 12.1 \mathrm{~mm}$ and $12.2 \mathrm{~mm}$ respectively. The diameter of the ascending aorta was determined to be $12.2 \mathrm{~mm}$ and descending aorta was $13.67 \mathrm{~mm}$. Ratio of the main pulmonary artery to ascending aorta was 1.06 , which was higher than the adult ration, usually taken as $<0.9$. Conclusion: The measurement criteria devised for early detection of pulmonary hypertension have different set of values when considering pediatric population as compared to adults. Main pulmonary artery to ascending aorta ratio is significantly higher in healthy children of all ages as compared to adults. CT scan is an excellent minimally invasive modality in evaluation of the mediastinal vasculature.
\end{abstract}

Key words: Pulmonary Artery to Ascending Aorta Ratio, CT Chest, Healthy Children, Pulmonary Hypertension.

Article Citation: Nasrullah F, Mahmood R, Hameedi S. Pulmonary artery and aortic diameters; measurement with calculation of main pulmonary artery to ascending aorta ratio in healthy children, using CT as diagnostic modality. Professional Med $\mathrm{J}$ 2017;24(10):1476-1479. DOI:10.17957/TPMJ/17.4041

\section{INTRODUCTION}

Pulmonary hypertension is described progressively persistent elevation of the pulmonary artery pressure leading to right heart failure. It is characterized by mean pulmonary arterial pressure $>25 \mathrm{~mm} \mathrm{Hg}$ at rest ${ }^{1}$ or $>30$ $\mathrm{mm} \mathrm{Hg}$ during exercise with pulmonary capillary wedge pressure $\leq 15 \mathrm{~mm} \mathrm{Hg}$, measured by right heart catheterization. ${ }^{2-3}$

The number of chest CT scans performed in patients with respiratory symptoms is on the rise, as it is fast, non-invasive and provides greater detail with more precision. The main pulmonary artery and ascending aorta are clearly visualized in the CT chest and the diameters can be easily measured. Enlarged main pulmonary artery, taken at the level of bifurcation, is usually taken as a manifestation of pulmonary hypertension, with the diameter $\geq 29 \mathrm{~mm} \mathrm{Hg}$ used as general predictive cut-off. ${ }^{1,4-5}$ Framingham heart study ${ }^{6}$ depicted cut-off values of $29 \mathrm{~mm}$ for males and $27 \mathrm{~mm}$ for females on CT scan. The same study establishes main pulmonary artery to ascending aorta ratio, obtained on an axial image, at the level of bifurcation of main pulmonary artery, to be $<1(0.9)$.

Pulmonary hypertension in children is also delineated by the same principle i.e. mean arterial pressure of $>25 \mathrm{~mm} \mathrm{Hg}$, as no separate criteria exists for diagnosing pulmonary hypertension in the pediatric population. The number of studies involving the abovementioned parameters, in pediatric population, is scarce. A study performed on the pediatric population by Compton et-al ${ }^{7}$, 
showed that that the main pulmonary artery to the ascending aorta ratio in children of all ages was statistically higher than the adults i.e. greater than 1 and closer to 1.09 .

The aim of this study is to measure the diameters of the main pulmonary artery and ascending aorta with calculation of the main pulmonary artery to ascending aorta ratio, in healthy children with no history or predisposing cause of pulmonary hypertension, on axial images of CT scan chest, performed for other indications. This would help in correct identification of the children at risk, using age appropriate values of the above parameters, who are referred to physician for further confirmation. This would result in early diagnosis, therapy and follow up leading to a more favorable prognosis.

\section{METHODOLOGY}

The study was conducted in Radiology Department, Combined Military Hospital, Peshawar, from 15 July 2015 to 14 July 2016. 283 children, referred to radiology department, $\mathrm{CMH}$ Peshawar, for CT scan of the chest were evaluated. Non-probability, purposive sampling was done. The study was approved by institute's ethical committee for research.

Pediatric patients, less than 16 years of age, with no history or predisposing causes of pulmonary hypertension, were included in the study. Patients with any predisposing cardiopulmonary disease, like lung parenchymal disorder, congenital heart disease, mediastinal mass, thoracic malformation, prior radiotherapy or chemotherapy were excluded from study to overcome confounding factors and bias in results. The patients were divided into 4 groups according to age. CT chest performed with routine protocols was studied. The results of the study were interpreted by consultant radiologists. Results were kept confidential and only concerned patients were informed. Examinations were performed at 128 slice multi detector row scanners CT machine, either with or without intravenous contrast.

\section{RESULTS}

Mean age of the study population was 5 years with ages ranging between 1 to 15 years. 156 patients were male $(55.1 \%)$ and 127 patients were female (44.9\%). The average diameter of the main pulmonary artery was $19 \mathrm{~mm}$, right pulmonary artery was $12.1 \mathrm{~mm}$ and left pulmonary artery was $12.2 \mathrm{~mm}$. The diameter of the ascending aorta was determined to be $12.2 \mathrm{~mm}$ and descending aorta was $13.67 \mathrm{~mm}$. Ratio of the main pulmonary artery to ascending aorta was 1.06 , which was higher than the adult ratio, usually taken as $<0.9$. Average of diameter of vessels for different age groups is shown in Table-I. The percentages of ratio of main pulmonary artery to ascending aorta for all age groups are depicted in Table-I.

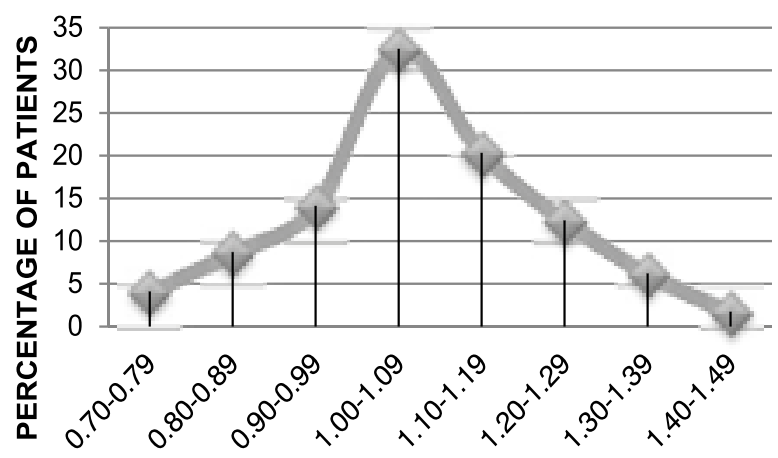

MAIN PULMONARY ARTERY TO ASCENDING AORTA RATIO

Figure-1. Percentages of ratio of main pulmonary artery to ascending aorta for all age groups

\begin{tabular}{|c|c|c|c|c|}
\hline Vessel & $0-3$ years & 4-7 years & 8-11 years & $12-15$ years \\
\hline Main pulmonary artery (mm) & 14.0 & 17.8 & 20.8 & 23.4 \\
\hline Right pulmonary artery (mm) & 8.4 & 10.9 & 13.3 & 15.9 \\
\hline Ascending aorta (mm) & 12.9 & 16.0 & 19.9 & 23.2 \\
\hline Descending aorta (mm) & 9.2 & 12.5 & 15.1 & 17.9 \\
\hline
\end{tabular}

Table-I. Average of diameter of vessels for different age groups $(n=283)$ 


\section{DISCUSSION}

Pulmonary hypertension is a life threatening disease, which presents late, as the patients only become symptomatic during late disease. ${ }^{8-10}$ Right heart catheterization is considered the gold standard for diagnosis ${ }^{11}$, however it is an invasive procedure and associated with a number of complications. Echocardiography is a non-invasive procedure to diagnose pulmonary hypertension but it has suboptimal accuracy, when compared with right heart catheterization. ${ }^{12-14}$ Increased pressure within the pulmonary vessels, leads to enlargement of the pulmonary artery with elevated main pulmonary artery to ascending aorta ratio. All these parameters can easily be measured on the CT scan chest; hence it provides an easy, fast and reliable method of indicating pulmonary hypertension. Raised main pulmonary artery to ascending aorta ratio $(>0.9)$ itself is significantly associated with an increased risk of death, regardless of presence or absence of coronary artery disease. ${ }^{15}$

In this study, we used non ECG - gated chest CT scans of healthy children to measure the diameters of mediastinal vessels. Diameters of the main pulmonary artery, right and left pulmonary artery, ascending and descending aorta were measured and arranged according to age. The average diameter of the main pulmonary artery was 19 $\mathrm{mm}$, right pulmonary artery was $12.1 \mathrm{~mm}$ and left pulmonary artery was $12.2 \mathrm{~mm}$. The diameter of the ascending aorta was determined to be 12.2 $\mathrm{mm}$ and descending aorta was $13.67 \mathrm{~mm}$. The main pulmonary artery to ascending aorta ratio was calculated, at the level of bifurcation of main pulmonary artery, and average ratio was found out to be 1.06. This was higher than the average ratio in adults, which is taken as $<0.9$.

Only few studies have been performed involving the abovementioned parameter in children. Compton et-al performed a study ${ }^{7}$, which showed the normal main pulmonary artery to ascending aorta ratio in children on MDCT is greater than 1 and closer to 1.09. These findings are consistent with our study. There are minor differences which may be due to differences in the sample population or sample size.

\section{CONCLUSION}

The criteria for diagnosis of pulmonary hypertension on chest CT i.e. main pulmonary artery to ascending aorta ratio of $<1$, is not applicable to children. In the pediatric age group, even healthy children show main pulmonary artery to ascending aorta ratio of $>1$. In our study, this ratio was calculated to be approximately 1.06. Hence, a higher ratio should be used as a cut-off for diagnosis of pulmonary hypertension in pediatric population, which should further be tested by right heart catheterization.

Copyright (C) 15 Aug, 2017.

\section{REFERENCES}

1. Peña $E$, Dennie $C$, Veinot $J$ et-al. Pulmonary hypertension: how the radiologist can help. Radiographics. 2012; 32 (1): 9-32.

2. Galiè N, Torbicki A, Barst R et-al. Guidelines on diagnosis and treatment of pulmonary arterial hypertension. The Task Force on Diagnosis and Treatment of Pulmonary Arterial Hypertension of the European Society of Cardiology. Eur. Heart J. 2004; 25 (24): 2243-78.

3. Badesch DB, Abman SH, Simonneau G et-al. Medical therapy for pulmonary arterial hypertension: updated ACCP evidence-based clinical practice guidelines. Chest. 2007; 131 (6): 1917-28.

4. Collins J, Stern EJ. Chest radiology, the essentials. Lippincott Williams \& Wilkins. (2007) ISBN: 0781763142.

5.0 Frazier AA, Galvin JR, Franks TJ et-al. From the archives of the AFIP: pulmonary vasculature: hypertension and infarction. Radiographics. 2000; 20 (2): 491-524.

6. Truong QA, Massaro JM, Rogers IS et-al. Reference values for normal pulmonary artery dimensions by noncontrast cardiac computed tomography: the Framingham Heart Study. Circ Cardiovasc Imaging. 2012;5 (1): 147-54.

7. Compton G, Florence J, MacDonald C et-al. Main pulmonary artery to ascending aorta diameter ratio in healthy children on MDCT. American Journal of Roentgenology. 2015; 205 (6):1322-25.

8. Brown $\mathrm{LM}, \mathrm{Chen} \mathrm{H}$, Halpern $\mathrm{S}$, et al. Delay in recognition of pulmonary arterial hypertension: factors identified from the REVEAL Registry. Chest. 2011; 140:19-26.

9. Thenappan T, Shah SJ, Rich S, Gomberg-Maitland M. A USA-based registry for pulmonary arterial hypertension: 1982-2006. Eur Respir J. 2007; 30:1103- 
1110.

10. Humbert $M$, Sitbon $O$, Chaouat $A$, et al. Pulmonary arterial hypertension in France: results from a national registry. Am J Respir Crit Care Med. 2006; 173:1023-1030.

11. Badesch DB, Champion HC, Sanchez MA, et al. Diagnosis and assessment of pulmonary arterial hypertension. J Am Coll Cardiol. 2009; 54:S55-66.

12. Bossone E, Bodini BD, Mazza A, Allegra L. Pulmonary arterial hypertension: the key role of echocardiography. Chest. 2005; 127:1836-1843.

13. Hsu VM, Moreyra AE, Wilson AC, et al. Assessment of pulmonary arterial hypertension in patients with systemic sclerosis: comparison of noninvasive tests with results of right-heart catheterization. JRheumatol. 2008; 35:458-465.

14. Swanson KL, Utz JP, Krowka MJ. Doppler echocardiography-right heart catheterization relationships in patients with idiopathic pulmonary fibrosis and suspected pulmonary hypertension. Med Sci Monit. 2008; 14:CR177-82.

15. Nakanishi R, Rana JS, Shalev A, Gransar H, Hayes SW, Labounty TM, et al. (2013) Mortality risk as a function of the ratio of pulmonary trunk to ascending aorta diameter in patients with suspected coronary artery disease. Am J Cardiol 111: 1259-1263.

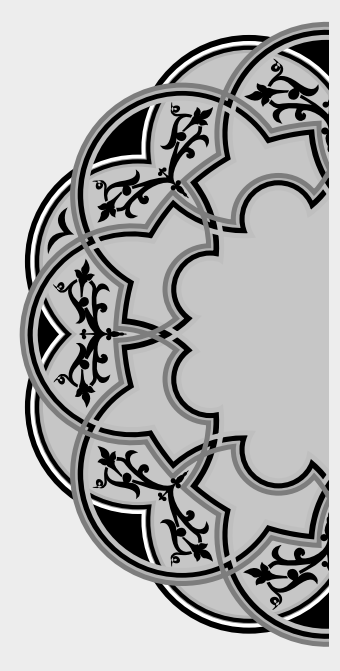

\title{
"Make yourself a priority once in a while. It's not selfish, It's necessary."
}

\author{
Unknown
}

\section{AUTHORSHIP AND CONTRIBUTION DECLARATION}

\begin{tabular}{|c|c|c|c|}
\hline Sr. \# & Author-s Full Name & Contribution to the paper & Author $=\mathbf{s}$ Signature \\
\hline 1 & Faran Nasrullah & $\begin{array}{l}\text { Principal author, Proposed } \\
\text { topic basic study design, } \\
\text { Methodology and } \\
\text { manuscript writing, Data } \\
\text { collection. }\end{array}$ & \\
\hline 2 & Rashid Mahmood & $\begin{array}{l}\text { Co-Author, Literature } \\
\text { review, Referencing and } \\
\text { quality unsurer. }\end{array}$ & \\
\hline 3 & Shahlisa Hameedi & $\begin{array}{l}\text { Co-author, Data collection, } \\
\text { Statistical analysis \& } \\
\text { interpretation of results }\end{array}$ & $d i$ \\
\hline
\end{tabular}

